\title{
Myasthenic decrement and myasthenic myopathy. A study on the effects of thymectomy ${ }^{1}$
}

\author{
PAOLO PINELLI, ANTONIO ARRIGO, AND ARRIGO MOGLIA
}

From the Clinic of Nervous and Mental Diseases, University of Pavia, Pavia, Italy

SYNOPSIS Motor unit action potentials, $M$ responses to repetitive nerve stimulation, and anticholinesterase tests were investigated in 12 myasthenic patients before and after thymectomy. In six of them the endarterial acetylcholine test was also carried out. Responsiveness to ACTH or to prednisone treatment was evaluated before and after thymectomy. The typical myasthenic presynaptic disorders were improved by thymectomy, while signs of myasthenic myopathy (according to Rowland's definition) were apparently increased. This process of 'functional myopathophanerosis' is discussed and explained in terms of a previous presynaptic disorder blocking the voluntary recruitment threshold of those motor units which are most affected at both presynaptic and postsynaptic level.

On the basis of statistical evaluations (Simpson, 1958), thymectomy is recognized as a useful procedure in the treatment of myasthenia gravis, but further experience shows that not all cases benefit from it to the same extent (Reinglass and Brickel, 1973); the unfavourable prognostic significance of thymoma is rather limited, while the most puzzling fact is that myasthenia gravis may start after thymectomy (Koch et al., 1970).

In order to understand better the effects of this operation it seemed worth while to recognize the different kinds of disorders that occur in patients labelled as myasthenic and to test them before and after thymectomy to see which was more affected.

The complex relationship between myasthenia and thymic disorders requires a comprehensive comparison with syntropic (Klein and Lennartz, 1966) affections like polymyositis (Namba et al., 1973).

Three aspects of the functional derangement of myasthenia tested in our laboratory are:

1. Decrement of evoked muscular action potentials ( $M$ responses) to supramaximal electrical stimulation. The results compare with the effect of hemicholinium intoxication and may

\footnotetext{
1 Paper presented at the Third International Congress of Muscle Diseases, Newcastle upon Tyne, 1974.

(Accepted 10 February 1975.)
}

be considered as a sign of presynaptic disorder. The decrement in myasthenic patients has been previously evaluated (Pinelli, 1957). Behaviour of voluntarily recruited single motor unit action potentials (MUPs) has also been studied.

2. After-facilitation, which represents a disorder similar to experimental mild curarization, may depend, at least partly, upon a block at post-synaptic receptor sites (Pinelli, 1972).

3. In portio affection of motor units with MUPs of short duration and small amplitude with no sign of neuronal impairment in these conditions may reasonably be interpreted as a sign of myopathic change. Buchthal and Pinelli (1952) found values in the normal range in four of six cases. The duration of the MUPs was reduced in the remaining two cases. There was no correlation between clinical gravity and the parameters described. Oosterhuis et al. (1972) found reduced duration and amplitudes of some MUPs in the quadriceps femoris and deltoid muscles in myasthenic patients.

These findings, however, are of scanty practical value since the methodology applied was insufficient for statistical analysis.

In fact, they have found the same values in normal subjects and in neurological patients without peripheral involvement.

In other words, the 'reduced duration and 
amplitude' correspond to the smallest normal MUP parameters.

The three types of myasthenic functional derangement may occur in different patients at a different rate.

If decrementing response predominates together with high anticholinesterase-sensitivity it is proper to speak of a 'myasthenic syndrome' (or presynaptic myasthenic component). If, on the other hand, after-facilitation and diminished MUP parameters prevail with poor anticholinesterase-sensitivity, a 'myasthenic myopathy' according to the definition of Rowland et al. (1973) may be acknowledged as an 'extension syndrome' from myasthenia gravis. It is often associated with thymoma. These symptoms may be considered as postsynaptic myasthenic component.

In a previous study of these parameters in non-thymectomized (22) myasthenic patients and thymectomized (24) myasthenic patients, we found a significant prevalence of myopathic signs in the second group. On the other hand, Savoldi et al. (1975) found a complete normalization of the Desmedt test (1973) in one out of six myasthenic patients and a partial normalization in four patients 20-30 days after thymectomy; this partial normalization was more marked in 50-70 days. This led us to follow up our research by keeping close control of patients before and after thymectomy.

\section{METHODS}

PATIENTS In a period of two years, systematic clinical evaluation of muscular strength, statistical EMG measurements, and edrophonium tests were performed in 12 myasthenic patients before and after thymectomy (Fig. 1). Six of them were also tested with endarterial acetylcholine. Their average age was 31 years, the youngest being 19 and the oldest 47 years of age. Seven patients were females. The average duration of the disease before thymectomy was 21 months with a range of three to 49 months.

Nine cases showed generalized myasthenic symptoms; cranial limb and trunk muscles were involved. Before thymectomy five patients showed slight or moderate inconstant defect of muscular strength which was rather well controlled by $180-540 \mathrm{mg}$ pyridostigmine daily. Four of them improved significantly after thymectomy. The remaining seven cases had more severe impairment with phases of
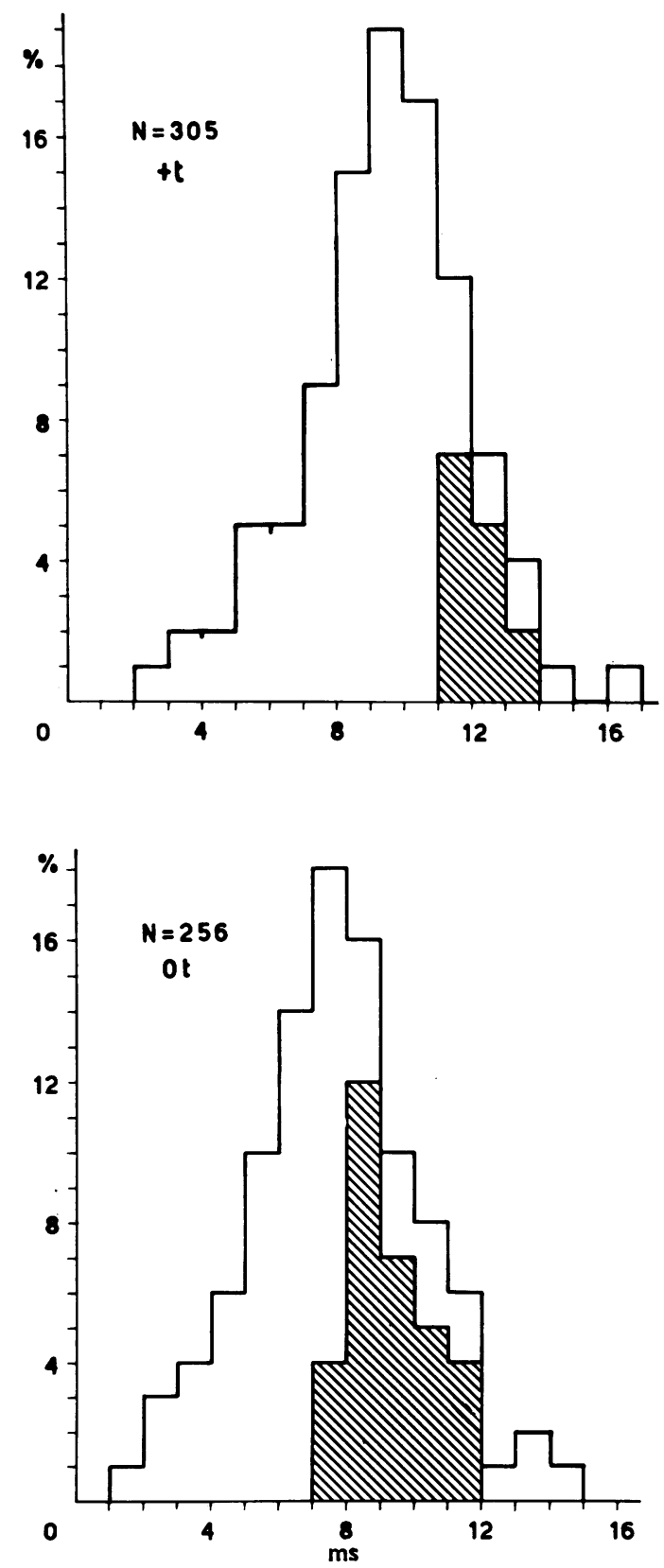

FIG. 1 Histograms of MUPs duration recorded from extensor digitorum manus in 12 myasthenic patients before thymectomy $(+\mathrm{t})$ and after thymectomy $(0 \mathrm{t})$. $=$ polyphasic a.p. 


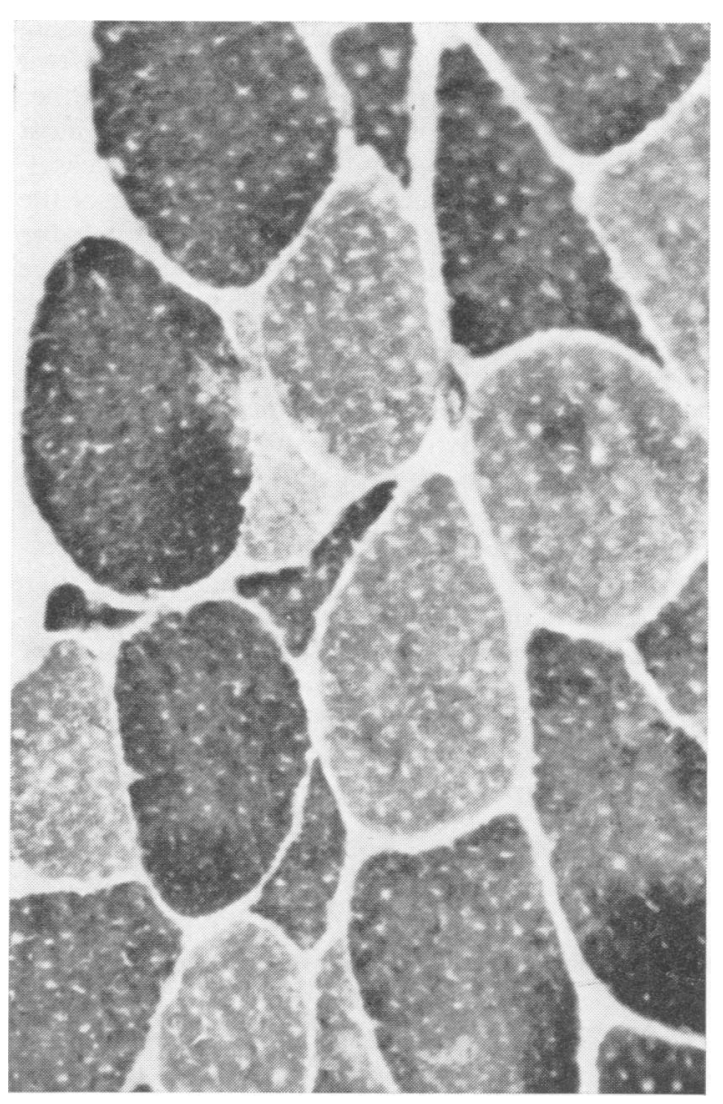

FIG. 2 Case 8. Deltoid muscle, before thymectomy. Neurogenic type atrophy of type 2 muscle fibres. ATPase direct staining (Padykula-Hermann), $\times 260$.

TABLE 1

MYASTHENIA (12 PATIENTS) RELATED TO SEVERITY, EXTENT, DURATION OF MYASTHENIC SYMPTOMS, SENSITIVITY TO ANTICHOLINESTERASE TREATMENT, ASSOCIATED SYMPTOMS, AND PRESENCE OF THYMOMA OF EPITHELIAL TYPE

\begin{tabular}{lcccc}
\hline & & $\begin{array}{c}\text { Cases } \\
\text { (no.) }\end{array}$ & $\begin{array}{c}\text { Improve } \\
\text { ment }\end{array}$ & a.T. \\
\cline { 4 - 5 } & & & $>6$ & $<6$ \\
\hline Severity & ++ & 7 & 5 & 2 \\
Extent & + & 5 & 4 & 1 \\
$\quad$ Mainly cranial & & 3 & 1 & 2 \\
$\begin{array}{l}\text { General } \\
\text { Preoperative duration }\end{array}$ & $\$ 6$ & 10 & 8 & 1 \\
$\begin{array}{l}\text { Anticholinesterase sensitivity } \\
\text { Associated symptoms }\end{array}$ & + & 2 & 2 & 2 \\
Thymoma of epithelial & + & 3 & 8 & 1 \\
$\quad$ type & - & 4 & 3 & 2 \\
& & 3 & 6 & 2 \\
\hline
\end{tabular}

Improved ( $>6)$. Not improved (<6). After thymectomy (a.T.).

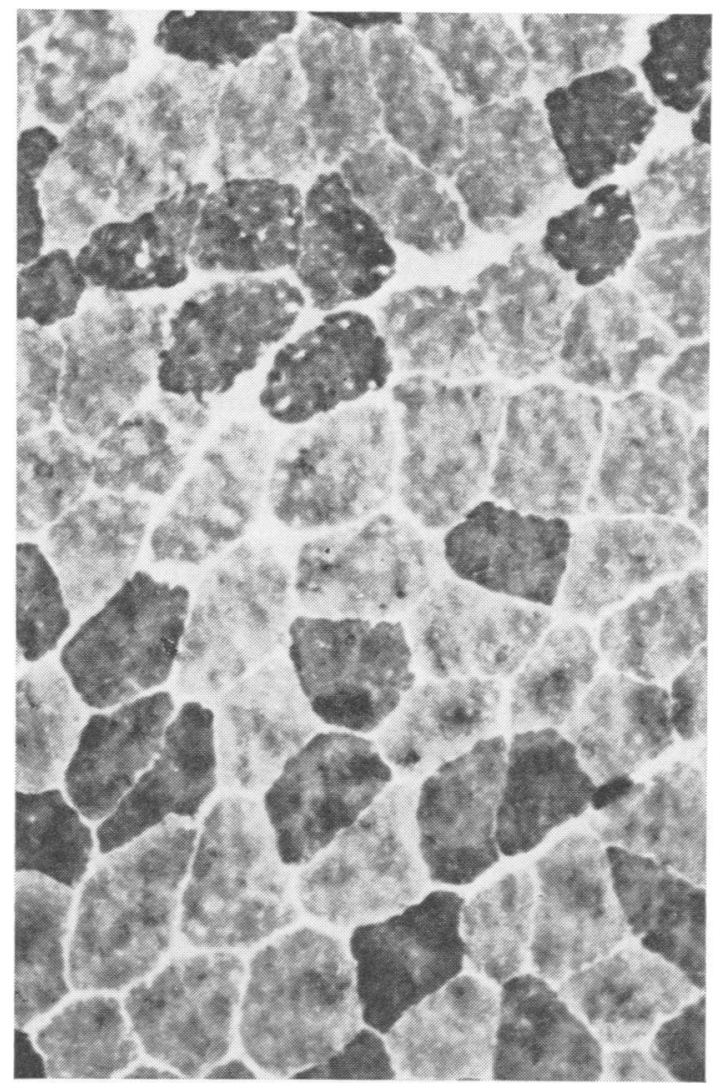

FIG. 3 Case 1. Deltoid muscle, before thymectomy. Predominance of type 1 muscle fibres. ATPase direct staining (Padykula-Hermann), $\times 160$.

deterioration which were not corrected by doses of pyridostigmine up to $900 \mathrm{mg}$ daily. In three of them a thymoma of epithelial type was found. Two patients did not improve after thymectomy. All patients were treated with at least one course of ACTH or of prednisone in a high dosage.

Laboratory studies gave normal findings except in one case where thyroid function was slightly increased $(+15 \%$ radioiodine uptake). In three patients the ESR was slightly increased for certain periods before thymectomy and it was normalized by local or general treatment of focal chronic infections (tonsillitis and sinusitis).

All clinical parameters and responses to thymectomy are given in Table 1 . Thymectomy was performed in four patients at the Institute of Clinical Surgery of the Catholic University in Rome (by the trans-sternal route) and on the other eight at the Institute of Surgical Pathology of Turin University 
(by the transcervical route). Thymoma of epithelial type was found in three cases and thymic hyperplasia in the other nine.

Muscle biopsy was performed in all cases before thymectomy. In three cases it showed a neurogenic type atrophy of type 2 muscle fibres (Fig. 2); in five cases there was predominance of type 1 muscle fibres (Fig. 3) and in four cases predominance of type 2 muscle fibres (Fig. 4).

CLINICAL EVALUATION Clinical evaluation of muscular strength was performed on patients under anticholinesterasic treatment three to five minutes after exercising for five minutes.

A sustained muscular maximal effort was rated at the end of a three minute duration according to the 10-point scale of the Mayo Clinic. This was done three times a day, twice weekly on the muscle

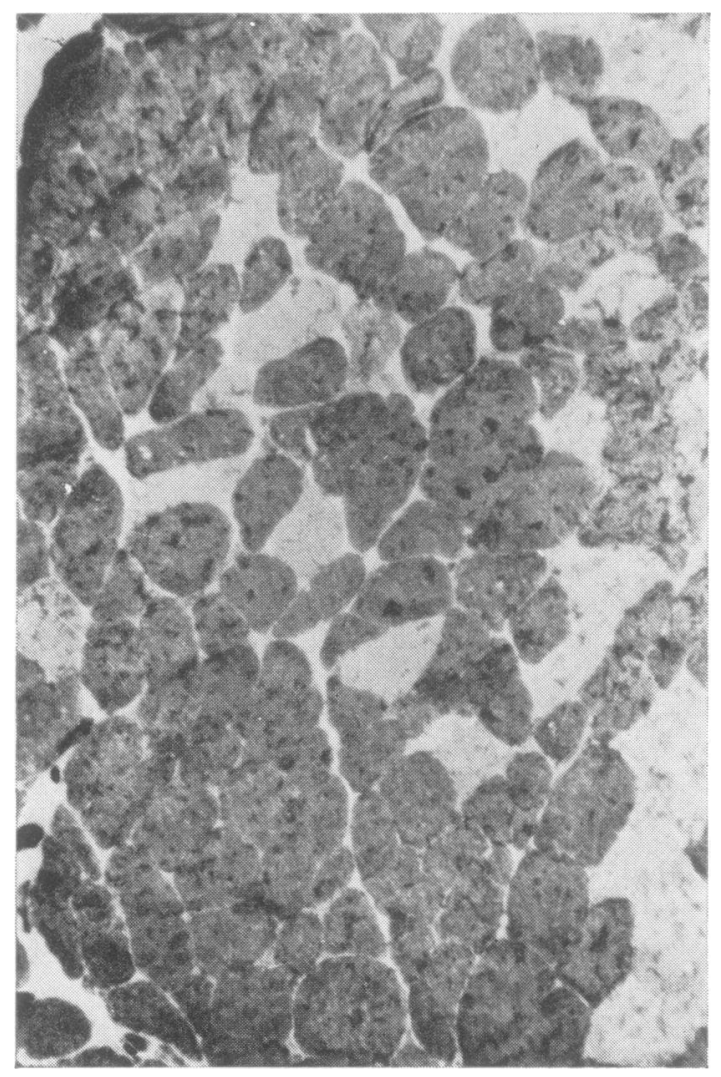

FIG. 4 Case 2. Deltoid muscle, before thymectomy. Predominance of type 2 muscle fibres. ATPase direct staining (Padykula-Hermann), $\times 160$. groups which were most affected. Dorsal stretching of the hand fingers was tested in all cases. In two patients abduction of the upper arm and in another two patients raising of the trunk proved the most affected muscle group, but even in these four cases, the strength of the extensor digitorum muscle of the hands was to some extent impaired. The tests were repeated a week later and again in one to three months, just before thymectomy. The average value of the 12 results obtained was taken as an index of the severity of the disease before thymectomy. The same examinations were performed for a week, 45 to 70 days after thymectomy and in another week seven to 10 months after operation. When, in both these periods, there was no significant increase of anticholinesterase treatment and the post-thymectomy score was more than two points higher than the average score before thymectomy, the improvement was judged as significant. An increase of three points average score later on was also considered as significant improvement, even if no improvement or some deterioration occurred in the first phase.

Since this rating was performed independently by two different neurologists whose evaluation was given as the final sum of these two scores, a total score of six or more (Tables 1 and 3) represents a significant improvement. A score of less than six points corresponds to nonsignificant change.

ELECTROMYOGRAPHY Electromyographic (EMG) investigations were performed with the technique described in previous papers (Pinelli, 1973).

Recording of spontaneous action potentials and of intensity/duration curves were routine. EMG interference activity was evaluated during maximal voluntary effort as peak-to-peak amplitude (mV).

MOTOR UNIT ACTION POTENTIALS PARAMETERS In order to collect homogeneous data, all the measurements were carried out on MUPs recorded from the extensor digitorum muscle of the hand on the more affected side in all patients.

Values for normal people in the same conditions at the same temperature are: average MUPs duration: $10.7 \mathrm{~ms} \pm 3 / \mathrm{ms}$; polyphasic potentials $11 \%$. The average amplitude is $0.32 \mathrm{mV} \pm 0.14$.

Special care was taken to record the same MUP during voluntary recruitment at slow frequency or during tonic activity (3-5/s); no change of duration, amplitude, or shape was found on successive action potentials of the same motor unit.

RESPONSES TO ELECTRICAL NERVE STIMULATION AT DIFFERENT FREQUENCIES The amplitude of the negative phase of the first response was measured. Decrement and after-facilitation were investigated 
and classified according to the criteria adopted in previous papers (Pinelli, 1967, 1972, 1973). Special care was taken to keep the stimulus intensity at actual maximal values during $3 / \mathrm{s}$ to $5 / \mathrm{s}$ stimulation.

ACETYLCHOLINE SENSITIVITY Evaluation of response to endarterial acetylcholine was carried out in six patients following the methodology adopted from Grob and described in previous studies (Pinelli et al., 1970 ) in which the results of normal subjects are also reported.

\section{RESULTS}

MOTOR UNIT POTENTIALS After thymectomy (a) the average duration $\left(\mathrm{t}_{\mathrm{a}}\right)$ of MUPs was diminished compared with the values found before thymectomy $\left(t_{b}\right)$ (Table 2; Fig. 1). On analysis $\eta=\left(t_{b}-t_{a}\right) /\left(\epsilon_{b}+\epsilon_{a}\right)=8$, indicating a high degree of significance.

The percentage of polyphasic motor unit potentials was increased from $14 \%$ to $32 \%$. The average amplitude of MUPs after thymectomy $(0.26 \mathrm{mV})$ was slightly decreased. The EMG interference pattern during maximal effort did not show changes of amplitude; the mean voltage was $1.9 \mathrm{mV}$ before thymectomy, $2.05 \mathrm{mV}$ after it. This slight increase, in spite of smaller and shorter MUPs, may be related to the improvement in maximal recruitment.

RESPONSE TO STIMULATION Decrement of responses to $3-5 / \mathrm{s}$ nerve stimulation was found in $60 \%$ of the patients before thymectomy, but in only $25 \%$ after it. On the other hand, an increase in amplitude of $M$ responses one to two minutes after previous repetitive stimulation ('after facilitation') was found at a faster rate of stimulation and in a larger number of patients after thymectomy (Table 2). For each individual patient the average $M$ response amplitudes before and after thymectomy were compared. No significant changes were found in four cases; in eight patients an increase was evident with an average value of $+55 \%$.

MYOPATHIC POST-THYMECTOMY FINDINGS AND COURSE OF THE DISEASE Substantial and constant improvement after thymectomy was not found in every case. In accordance with previous research, the presence of thymoma represents a factor of unfavourable prognosis, but not in all cases. On the other hand, even in cases of pure thymic hyperplasia, the course of the disease may be impossible to foresee (Reinglass and Brickel, 1973). Since in our cases no correlation was found with various clinical parameters (Table 1), we thought it worth while to investigate whether the EMG changes reported in Table 2 were related to the degree of response to thymectomy. Nine patients showed, during one year of observation, a substantial improvement which was rated degree 6 or more, according to the Mayo Clinic motor scale applied with the criteria reported in the preceding section. In those patients who responded well, the average value of MUPs duration before thymectomy was within the normal range $(9.8 \mathrm{~ms})$, while in the other less responsive patients it appeared shorter (8.6 ms).

Marked accumulation of mononuclear cells along muscle fibres (Fig. 5) was found in five cases out of nine in the first group and one out of three in the second group, but in both groups

TABLE 2

EMG FINDINGS IN 12 MYASTHENIC PATIENTS BEFORE AND AFTER THYMECTOMY*

\begin{tabular}{|c|c|c|c|c|c|}
\hline \multirow[t]{2}{*}{ Thymectomy } & \multirow[t]{2}{*}{$\begin{array}{c}\text { MUP } \\
(\text { no. })\end{array}$} & \multicolumn{2}{|c|}{$\begin{array}{c}\text { MUP } \\
\text { parameters }\end{array}$} & \multicolumn{2}{|c|}{$\begin{array}{l}\text { Electrical stimulation } \\
\text { (no. of patients with) }\end{array}$} \\
\hline & & $\begin{array}{l}\text { Duration } \\
\text { (ms) }\end{array}$ & $\begin{array}{c}\text { Polyphasic } \\
(\%)\end{array}$ & $\begin{array}{l}\text { Decrease } \\
\text { at } 3 / s\end{array}$ & $\begin{array}{c}\text { After- } \\
\text { facilitation }\end{array}$ \\
\hline $\begin{array}{l}\text { Before } \\
\text { After }\end{array}$ & $\begin{array}{l}256 \\
305\end{array}$ & $\begin{array}{l}9.2 \pm 2.30 \\
7.1 \pm 2.14\end{array}$ & $\begin{array}{l}14 \\
32\end{array}$ & $\begin{array}{l}8 \\
3\end{array}$ & $\begin{array}{l}4 \\
9\end{array}$ \\
\hline
\end{tabular}

* Number of motor unit action potentials (MUP) from extensor digitorum manus; mean duration and percentage of polyphasic action potentials. Number of patients showing $>10 \%$ amplitude decrease of fifth to tenth response from thenar muscles to maximal median nerve stimulation at $3-5 / \mathrm{s}$ or $>20 \%$ amplitude increase of the first response from the same muscles after previous 3-20/s stimulation. 
TABLE 3

SUBGROUPS OF RESULTS GIVEN IN TABLE 2, ACCORDING TO DEGREE OF IMPROVEMENT (SEE TABLE 1)*

\begin{tabular}{|c|c|c|c|c|c|c|c|c|}
\hline \multirow{2}{*}{$\begin{array}{l}\text { Improvement after } \\
\text { thymectomy }\end{array}$} & \multirow{2}{*}{$\begin{array}{l}\text { Patients } \\
\text { (no.) }\end{array}$} & \multirow{2}{*}{$\begin{array}{c}\text { Disease } \\
\text { duration } \\
(n)\end{array}$} & \multicolumn{3}{|c|}{$M U P s$} & \multicolumn{2}{|c|}{ Electrical stimulation } & \multirow{2}{*}{$\begin{array}{c}\text { Edrophonium } \\
\text { positive test }\end{array}$} \\
\hline & & & Thymectomy & $\underset{s}{\text { Duration }}$ & $\begin{array}{c}\text { Polyphasic } \\
\mathrm{s}\end{array}$ & $\begin{array}{c}\text { Decrease } \\
\text { at } 3 / \text { so }\end{array}$ & $\begin{array}{c}\text { After- } \\
\text { facilitation }\end{array}$ & \\
\hline$>6$ & 9 & $7-49$ & $\begin{array}{l}\text { Bt } \\
\text { At }\end{array}$ & $\begin{array}{l}9.8 \\
7.3\end{array}$ & $\begin{array}{r}7 \\
28\end{array}$ & $\begin{array}{l}7 \\
2\end{array}$ & $\begin{array}{l}2 \\
7\end{array}$ & $\begin{array}{c}9 \\
6+(3)\end{array}$ \\
\hline$<6$ & 3 & $6-34$ & $\begin{array}{l}\text { Bt } \\
\text { At }\end{array}$ & $\begin{array}{l}8.6 \\
6.8\end{array}$ & $\begin{array}{l}18 \\
35\end{array}$ & $\begin{array}{l}1 \\
1\end{array}$ & $\begin{array}{c}(2) \\
2\end{array}$ & $\begin{array}{l}(1) \\
(2)\end{array}$ \\
\hline
\end{tabular}

* For each group the values of MUP parameters, the number of cases with abnormal responses to iterative electrical nerve stimulation and their correction with intravenous edrophonium (number of cases with a poor correction shown in parentheses) before thymectomy (Bt) and after thymectomy (At).

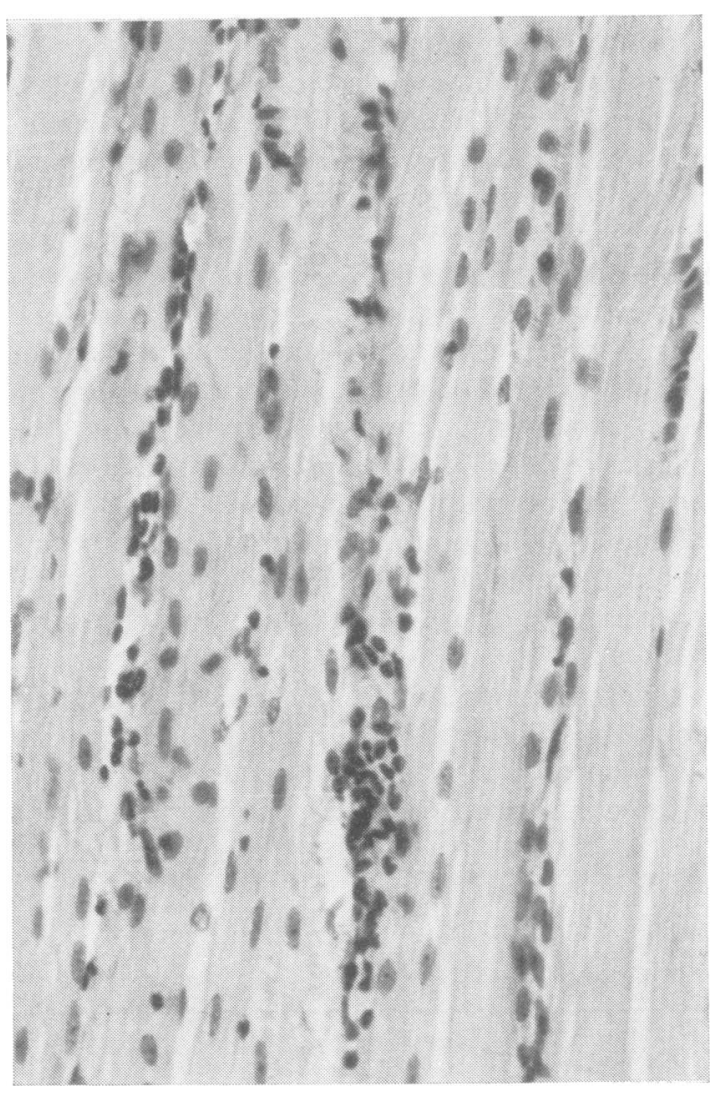

FIG. 5 Case 2. Deltoid muscle, before thymectomy. Accumulation of mononuclear cells along muscle fibres. Haematoxylin and eosin, $\times 160$. of patients MUP duration decreased after thymectomy. The decrease was larger in the more responsive patients (Table 3 ).

ABNORMAL RESPONSES TO ENDARTERIAL ACETYLCHOLINE The endarterial acetylcholine test has been carried out in only six patients of this group (Table 4). Within the limits of preliminary research two points stand out as worth mentioning. (1) The most abnormal response was represented by the occurrence of a late depression of evoked $M$ response in one patient and it remained unchanged after thymectomy. In this patient the improvement after thymectomy was slight and limited up to 40 days after operation.

\section{TABLE 4}

PROMPT AND LATE DEPRESSION OF M RESPONSES TO REPETITIVE SUPRAMAXIMAL STIMULATION OF MEDIAN NERVE AFTER ACETYLCHOLINE 2-5 MG BY ENDARTERIAL INJECTION IN SIX MYASTHENIC PATIENTS*

\begin{tabular}{|c|c|c|}
\hline \multirow{3}{*}{$\begin{array}{l}\text { Thymectomy } \\
\text { Before }\end{array}$} & \multicolumn{2}{|c|}{ Endarterial Ach } \\
\hline & $\begin{array}{c}\text { Ld. only } \\
1 \\
\text { ACTH }\end{array}$ & $\begin{array}{c}\text { Pd. }+ \text { Ld. } \\
5 \\
\text { ACTH }\end{array}$ \\
\hline & $\begin{array}{cc}\text { E. det. } & \text { Reg. imp. } \\
0 & \text { (1) }\end{array}$ & $\begin{array}{cc}\text { E. det. } & \text { Reg. imp. } \\
5 & 0\end{array}$ \\
\hline \multirow[t]{2}{*}{ After } & $\begin{array}{l}\text { Ld. only } \\
1 \\
\text { ACTH }\end{array}$ & $\begin{array}{c}\text { Pd. }+ \text { Ld. } \\
5 \\
\text { ACTH }\end{array}$ \\
\hline & $\begin{array}{ll}\text { E. det. Reg. imp. } & \text { (1) }\end{array}$ & E. det. Reg. imp. \\
\hline
\end{tabular}

- Pd.: prompt. Ld.: late depression. Ach.: acetylcholine.

The effects of high dosage ACTH treatment are also given: cases with early deterioration and later improvement (E. det.) or only improvement (Reg. imp.) are shown. Both orders of findings are given before and after thymectomy. 
(2) Five cases showed both prompt (irregular) and late depression (increased in comparison with normal subjects).

Four cases showed a sustained improvement after thymectomy but the abnormalities in responses to acetylcholine appeared unchanged.

ACTH AND PREDNISONE TREATMENT During high dosage of ACTH cycle administered before thymectomy all the patients deteriorated: in six patients this was not observed or remained within a very low grade, when the same treatment was carried out after thymectomy (Table 4).

After ACTH treatment a normal response to acetylcholine was noted (Pinelli et al., 1970).

\section{DISCUSSION}

THYMECTOMY EFFECTS: TENDENCY TO NORMALIZATION OF PRESYNAPTIC FUNCTION AND 'MYOPATHOPHANEROSIS' We may consider it as definitely confirmed that thymectomy induces in myasthenic patients a decrease in MUPs duration with an increase in proportion of polyphasic MUPs. These changes may be attributed to functional inactivity of some single fibres of the motor unit; and since the change is a constant one (measurements were made only on MUPs which were recorded at least three times as identical), we are inclined to consider it as a sign of in portio involvement of motor units. The absence of any sign of neuronal involvement (no fibrillation, normal intensity-duration curves) is in favour of a myopathic lesion. A comprehensive review of research in this field shows that the myasthenic disorder depends not only on presynaptic (Desmedt, 1973) but also on post-synaptic changes (Bonduelle and Bouygues, 1955; Pinelli et al., 1970; Johns et al., 1971a; Kott and Rule, 1973; Simpson, 1973). We found myopathic EMG change after thymectomy in accord with the occurrence of post-synaptic alterations that are not altered by the operation. The question, however, arises why they are not evident before thymectomy. Since this effect of thymectomy occurs while the patient is improving, it could not be a matter of myopathic involvement worsening, as there is no myopathogenic effect. On the other hand, this phenomenon was found at the same rate in patients with predominance of type 1 muscle fibres and in patients with type
2 predominance. We therefore postulate that, in non-operated myasthenic patients, there exists some hidden phenomenon: before thymectomy the presynaptic disorder obscures the postsynaptic one by some blocking effect. By correcting the first disorder, thymectomy permits the post-synaptic myopathic involvement to become evident. Therefore, while a myopathogenic effect is excluded, we may speak of some process of 'functional myopathophanerosis'. The following hypothesis is suggested: the presynaptic alteration may be more severe in motor units with the most marked postsynaptic involvement, and it may block, by some mechanism, their voluntary recruitment on slight effort.

This possibility is supported, to some extent, by the fact that even the patients with a significant decrease of the $M$ responses at 5/s nerve stimulation never show any decrement of MUPs during recruitment with slight voluntary effort.

Consequently, only the least affected motor units are recruited in these conditions and the EMG investigation shows normal-or nearly normal-values. The increase of interference pattern after thymectomy and the presence of smaller and shorter duration MUPs points to a block-correcting effect of the operation.

This hypothesis may also explain why the cases with a less marked presynaptic disorder will profit less by thymectomy (Table 3 ).

The persistence of the post-synaptic abnormalities shown by the acetylcholine test after thymectomy also shows a presynaptic action of thymectomy in myasthenia gravis.

SIMILARITIES AND DIFFERENCES BETWEEN MYASTHENIA GRAVIS AND POLYMYOSITIS In conclusion, we may argue from our data that, in myasthenia gravis, there is a myopathic involvement which remains latent at the EMG level because of some hidden effect related to a presynaptic neural involvement. Thymectomy exerts its beneficial influence on the presynaptic component of this disease, as we have been able to show, for a period of three to 10 months after the operation, while it should not be of any help for polymyositis where no presynaptic myasthenic alteration occurs. The fundamental disorder of polymyositis, according to the immunological hypothesis (Kott and Rule, 1973; Namba et al., 1973), has been considered, in 
some aspects, to be similar to the myopathic component of myasthenia gravis; it remains, however, basically different with respect to the enzymic abnormalities detectable in serum.

Our present study further underlines the different nature of the myopathic myasthenic component.

In our hypothesis, the myopathic component of myasthenia appears proportional to the degree of presynaptic involvement. This strongly suggests a dependence of the 'myasthenic myopathy' upon some neuronal trophic defect: a common neuronal partial affection would induce both a presynaptic acetylcholine deficit and a postsynaptic myopathic impairment.

On the other hand, the myopathic consequence, which may be conceived mainly in terms of receptor damage, often proceeds quite independently from the acetylcholine neuronal defect: it is not sufficiently corrected by thymectomy, while it may be favourably influenced by ACTH or prednisone treatment.

\section{REFERENCES}

Bonduelle, M., and Bouygues, P. (1955). Myasthénie et polymyosites. Le syndrome myasthénique des myosites. La myasthénie, syndrome ou maladie. Presse Médicale, 63, 1572-1575.

Buchthal, F., and Pinelli, P. (1952). Analysis of muscle action potentials as a diagnostic aid in neuro-muscular disorders. Acta Medica Scandinavica, 142, suppl. 266, 315-327.

Desmedt, J. E. (1973). The neuromuscular disorder in myasthenia gravis. 1. Electrical and mechanical response to nerve stimulation in hand muscles. In New Developments in Electromyography and Clinical Neurophysiology, vol. 1, pp. 241-304. Edited by J. E. Desmedt. Karger: Basel.

Johns, T. R., Campa, J. F., and Crowley, W. J. (1971b). Familial myasthenic myopathy. Neurology (Minneap.), 21, 449.

Johns, T. R., Crowley, W. J., and Miller, I. Q. (1971a). The syndrome of myasthenia and polymyositis with comments on therapy. Annals of New York Academy of Sciences, 183, 64-71.

Klein, H. O., and Lennartz, K. J. (1966). Zur Syntropie von
Myasthenia gravis, Polymyositis, Myokarditis und Thymom. Deutsche Medizinische Wochenschrift, 91, 17271730.

Koch, F., Regli, F., and Reinle, E. (1970). Myasthenia gravis nach Thymektomie. Vorstellung von zwei eigenen Patienten und Vergleich mit ähnlichen Fällen aus der Literatur. Schweizer Medizinische Wochenschrift, 100, 65-68.

Kott, E., and Rule, A. H. (1973). Myasthenia gravis. Cellular response to basic myelin protein compared with cellular and humoral immunity to muscle antigens. Neurology (Minneap.), 23, 745-748.

Namba, T., Brunner, N. G., and Grob, D. (1973). Association of myasthenia gravis with pemphigus vulgaris, Candida albicans infections, polymyositis and myocarditis. Journal of the Neurological Sciences, 20, 231-242.

Oosterhuis, H. J. G. H., Hootsmans, W. J. M., Veenhuyzen, H. B., and Zadelhoff, I. Van (1972). The mean duration of motor unit action potentials in patients with myasthenia gravis. Electroencephalography and Clinical Neurophysiology, 32, 697-700.

Pinelli, P. (1957). Sul disturbo fondamentale della miastenia e sulle sindromi e disturbi miasteniformi. Rivista di Patologia Nervosa e Mentale, 78, 121-267.

Pinelli, P. (1967). Effetti della somministrazione subacuta di dosi discrete di ACTH nella miastenia di medio grado. (Studio elettromiografico seriale.) Rivista di Neurologia, 37, 343-365.

Pinelli, P. (1972). Reperti di 'blocco reversibile' nella miastenia. Riunione Neurologica di Viterbo, 1972. Lavoro Neuropsichiatrico, 1972. (In press.)

Pinelli, P. (1973). Miastenia grave e miopatia miastenica corticosensibile-Decorso della malattia e valutazione dei reperti neurofisiologici alla luce delle ipotesi di Simpson. XVIII Congresso della Società Italiana di Neurologia, Roma, 1973. Rivista di Patologia Nervosa e Mentale. (In press.)

Pinelli, P., Tonali, P., Gambi, D., and Pelliccioli, G. (1970). Sul blocco neuromuscolare da introduzione endoarteriosa di acetilcolina. Effetti di trattamenti preliminari con ACTH. Rivista di Neurologia, 40, 203-212.

Reinglass, J. L., and Bricket, A. C. J. (1973). The prognostic significance of thymic germinal center proliferation in myasthenia gravis. Neurology (Minneap.), 23, 69-72.

Rowland, L. P., Lisak, R. P., Schotland, D. L., DeJesus, P. V., and Berg, P. (1973). Myasthenic myopathy and thymoma. Neurology (Minneap.), 23, 282-288.

Savoldi, F., Moglia, A., Nappi, G., Poloni, M., Scelsi, R., and Arrigo, A. (1975). Ricerche preliminari clinicoelettromiografiche sugli effetti della timectomia nella miastenia grave. Rivista di Neurologia. (In press.)

Simpson, J. A. (1958). An evaluation of thymectomy in myasthenia gravis. Brain, 81, 112-144.

Simpson, J. A. (1973). Tolleranza immunologica e miastenia. Il ruolo del timo nell'accrescimento e nella differenziazione. XVIII Congresso della Società Italiana di Neurologia, Roma, 1973. Rivista di Patologia Nervosa e Mentale. (In press.) 